\title{
A NEUTRAL FORM FOR EXPERIENTIAL MATERIAL CHARACTERISATION
}

\author{
Veelaert, Lore; Moons, Ingrid; Rohaert, Sarah; Du Bois, Els \\ University of Antwerp - Department of Product Development
}

\begin{abstract}
Materials experience in design involves the meanings that materials convey to users through its expressive characteristics. Such meaning evoking patterns are influenced by parameters such as context, product (e.g.shape) and user. Consequently, there is a need to standardise experiential material characterisation and large-scale data collection, by means of a meaning-less or 'neutral' demonstrator to objectively compare materials.

This paper explores the conception of this neutrality and proposes two opposing strategies: neutrality through complexity or through simplicity. In a pre-study with 20 designers, six associative pairs are selected as neutrality criteria, and shaped in 240 forms by 20 (non) designers in a main workshop. Following the simplicity strategy, these forms are averaged out in three steps by a team of five designers, based on a consensus on of delicate-rugged, aggressive-calm, futuristic-calm, masculine-feminine, traditional-modern, and toylike-professional, resulting in a selection of four averaged neutral forms.

Finally, future research will focus on complexity to increase interactivity, so that consumers might be triggered in extensive material exploration.
\end{abstract}

Keywords: User centred design, Multisensory product experience, Human behaviour in design, Material demonstrator, Materials Experience

\section{Contact:}

Veelaert, Lore

University of Antwerp

Product Development

Belgium

lore.veelaert@uantwerpen.be

Cite this article: Veelaert, L., Moons, I., Rohaert, S., Du Bois, E. (2019) 'A Neutral Form for Experiential Material Characterisation', in Proceedings of the 22nd International Conference on Engineering Design (ICED19), Delft, The Netherlands, 5-8 August 2019. DOI:10.1017/dsi.2019.180 


\section{INTRODUCTION}

In our changing consumer market, marked by ever increasing expectations of users, industrial designers are challenged to develop products that go beyond mere product utility, functionality and performance. Indeed, from the perspective of user-centred design, there is a growing emphasis on the consumer in each step of the design process in order to design meaningful product experiences that appeal to the broad consumer market (Hassenzahl, 2013). Van Kesteren (2008, p. 23) states that "product designers have to use their experience, together with expertise from market researchers and consumers to predict and evaluate the user-interaction qualities with a product for predefined target groups".

Traditionally, design arises at the intersection of materials, shapes and technique (Ashby and Johnson, 2012). As product ideas are made physical by means of materials, materials are a basic attribute of products, and thus, materials selection plays a significant role in industrial design (Deng and Edwards, 2007; Hodgson and Harper, 2004).

Literature suggests multiple approaches for an ideal materials selection process (Ashby et al., 2004; Chiner, 1988; Farag, 2002; Jalham, 2006; Van Kesteren et al., 2006), however they mostly originate from material science and mechanical engineering, that reflects on "what a material is and how it behaves" (Camere and Karana, 2018, p. 1), for example in terms of tensile strength, E-modulus, hardness, etc. In contrast, less attention is given to the field of 'materials experience', which involves the meanings that materials can convey to users through its expressive characteristics (Karana et al., 2010). This meaning driven materials selection builds upon four levels of experiential material characteristics such as sensorial attributes (e.g. soft, glossy, warm), interpretive (meanings or associations, e.g. masculine, futuristic, toy-like), affective (emotions, e.g. surprise, curiosity) and even performative characteristics (actions) (Camere and Karana, 2018). This paper aims to take the first steps in enhancing meaning driven materials selection for designers, by means of exploring possible standard, neutral forms that can be used for experiential material characterisation at first, and potentially for materials selection in future research.

\section{CHALLENGES IN EXPERIENTIAL CHARACTERISATION OF MATERIALS}

Despite the growing attention for the meanings that materials can express, there is still a need to standardise the data collection of experiential characteristics, as they exist for the technical, economic and ecological characteristics that are mostly found in databases (Zarandi et al., 2011). In fact, we experience a drawback in the fundamental or systematic data collection on this level, since there is no equivalent support available for experiential characteristics (Ashby and Johnson, 2012). Most databases are information-based and provide an extensive amount of numerical, technical data for an excessive amount of materials, such as the CES database (Ashby and Cebon, 2007), where you can select materials based on constraints. By contrast, inspiration-based databases usually involve a limited amount of materials than can be explored and discovered in a more visual way, making it more attractive for designers, particularly in early design stages (Ramalhete et al., 2010). Moreover, such inspiration resources can occur both online and physical, going from CES' 'Product, Materials and Processes Database' (Granta, 2016) to an extensive website and exhibition events of Material District (Material District, 2019). Here, designers can experience innovative material samples first hand, making its properties more tangible. However, these samples are mostly semi-finished or final applications, and difficult to objectively compare, hence a standardised material sample demonstrator is required to evaluate experiential qualities.

For that matter, semantic differential scales are used in order to compare and characterise materials by means of scoring pairs of opposite adjectives, such as cold versus warm and aggressive versus calm (Karana et al., 2009; Osgood et al., 1957). Currently, three main constraints can be found with regard to experiential material data collection: (i) data is merely collected on small-scale projects or workshops with specific material cases, (ii) assessment is usually done by a limited team of designers instead of consumers, and (iii) comparisons are mostly made between material families such as metal versus wood versus plastic (Crippa et al., 2012; Karana et al., 2009).

The difficulty in generating knowledge on materials experience lies in the fact that these meaning evoking patterns are influenced by various subjective parameters such as the context (time, place, etc.), the product (including shape, function, brand, etc.) and the user him/herself (Karana, 2009). To that regard, Karana et al. (2007) conducted four studies to investigate the effect of form in particular on a material's meaning. Indeed, metal that is embodied in a rather sharp form may be more associated 
with aggressiveness than metal used in a soft-edged bowl for example. Form can be defined as "the boundary of matter by which we distinguish these objects from each other and their environment" (Karana et al., 2007; Muller, 2001).

Previous studies on experiential characterisation of materials use different kinds of stimuli or sample demonstrators to conduct their experiments. At first, photographs or renders of material are used for easy online surveys (Agost and Vergara, 2014; Karana et al., 2007), and as in previous work (Veelaert et al., 2018) where different materials were rendered on abstract forms. However, this option offers no physical interaction with the material itself and makes it hard to compare within material classes.

Second, material samples made from a technical perspective can be employed, for example test bars from the injection moulding machine (Veelaert, Du Bois et al., 2017a) or a sample 'Determinator' (Veelaert, Hubo et al., 2017b) that illustrates different technical properties on different virgin and recycled plastics. The advantage here lies in the standardisation and thus comparability, since each sample has the exact same dimensions in each material. The disadvantage however, is that these samples are not optimised for experiential characterisation and are not attractive for consumers to interact with, as opposed to designers who have more experience in abstract thinking in this context.

Third, flat equal-sized samples are used, allowing participants to look at the material (Sauerwein et al., 2017; Wastiels et al., 2012), blindly touch the material (Etzi et al., 2014; Sakamoto and Watanabe, 2017; Zuo et al., 2001), and/or visually touch the material with their fingers (Piselli et al., 2018; Sauerwein et al., 2017; Wastiels et al., 2012; Zuo et al., 2001). However, free exploration of the material is rather limited due to the flat, non-interactive form, which does not offer the consumer a real feel of the material but are rather seen as boring, as is also the case when using sphere forms that have only one view from each angle.

Fourth, sample demonstrators are also materialised in products (Fenko et al., 2010; Karana et al., 2009). Of course, finding or making products in different materials within one class can be less feasible. For instance, Crippa et al. (2012) used nine bowls in different materials families for their study on emotions. This familiar and simple-shaped object was chosen to freely experience the materials while maintaining the same function. Nevertheless, the bowl did not have exactly the same dimensions (partly as a consequence of the material and its production technique), and the function of a bowl could have elicited food-related associations. Indeed, wood might be considered less pleasant instead of ceramics in this context, although this might not be inherently true for this material. In contrast, literature indicates that more experiments with products are conducted with non-professional participants as well, illustrating their greater ability to attract consumers' interest.

To sum up, the results and discussions of previous studies confirm that material meanings are indeed influenced by user, form and function. There is a knowledge gap in experiential consumer data on materials, beyond existing data from small-scale workshops or specific material cases. Hence, if experiential material data is needed, how can we collect such data in an 'objective' and standardised manner? Moreover, when trying to collect such large-scale data not only from designers, but from consumers specifically, we encounter additional challenges; how to interact with him/her on such an abstract topic? Consequently, there is a clear need for a material sample demonstrator for user-centred or experiential evaluation of materials. First of all, this demonstrator must be a physical object to fully enable the sensorial experience. Next, in order to include the consumer in the characterisation process, it must be attractive and accessible to non-designers; it must trigger them to interact with the sample object. Last, it must facilitate an objective comparison between materials, minimising external influences on associations, hence, the sample form must be as 'neutral' or 'meaning-less' as possible. On the basis of such standard form, 'neutral' material data can be collected. Moreover, materials can be envisioned in different contexts for objective, yet context-specific data as well. In this way, new contexts will not be excluded, and innovation is not impeded, while maintaining practical feasibility (physical samples, equal form, and simultaneously re-usable in different contexts).

Consequently, this paper elaborates on the exploration into material demonstrators according to a hypothesised simplicity strategy, as discussed in Section 3 that examines the concept of neutrality and proposes form-related criteria for neutrality in a pre-study. Next, a framing methodology of Research By Design is applied in Section 4 that describes four successive design phases in the creation of neutral demonstrators. Finally, Section 5 discusses the findings. 


\section{EXPLORING THE CONCEPTION OF NEUTRALITY}

In this regard, what is neutral? As human beings, we tend to give meaning to everything we see and experience, trying to categorise and identify it, hence, meaning is subjective and dynamic in its nature, and influenced by individual parameters (Krippendorff and Butter, 1984; Osgood et al., 1957). Consequently, we could reason that neutrality does not exist. For example, Thaler and Sunstein (2008, p. 3) state that "there is no such thing as a "neutral" design". However, we could also argue that things can be more or less neutral than others. Therefore, we hypothesise that two conceptions of neutrality can be formulated, and/or two opposing strategies can be followed to obtain neutrality: simplicity versus complexity.

- On the one hand, neutrality can be based on the idea of simplicity, meaning that the object does not evoke any feelings. It is neither one meaning (e.g. aggressive) nor the other (e.g. calm).

- On the other hand, conceiving neutrality as complexity means that the object has a wide range of meanings at the same time of which the user is not able to assign to known archetypes. The object elicits a combination of several meanings (e.g. aggressive and calm at the same time).

First, an exploration aims to corroborate the hypothesis about the two conceptions of neutrality by examining the concept of neutrality (both on a theoretical and a physical level) to further clarify the definitions and examples (see Figure 1). Second, this section aims to select a set of associative pairs as criteria for (non) neutral forms.

\subsection{Pre-study 1 - Two conceptions of neutrality}

This pre-study intends to explore and define the concept of neutrality. Therefore, twenty design students $(\mathrm{N}=20)$ from the Department of Product Development of the University of Antwerp are asked an open-ended question about what neutrality means to them (How would you define form neutrality?). Next, 27 design students $(\mathrm{N}=27)$ of the second bachelor Product Development are asked to create a neutral form by means of plasticine and to explain why they made that specific form. Design students were chosen as they are trained in abstract thinking in forms and shapes but can still relate sufficiently to consumers' experience.

In the first part, twelve out of twenty responses include references to the aspect of our simplicity definition (not choosing sides, simple, in the middle, not extreme, mean of extremes, etc.). Other respondents describe neutrality as objectivity, rational, impartial, etc. In contrast, the second part includes forms that can be classified in a simplicity group (fourteen results) and a complexity group (thirteen results). Figure 1 shows a couple of the created forms. Generally, simple forms show round edges in balls, spheres, or other basic forms, opposed to the complex forms.

Conclusively, the results of this first pre-study supports our hypothesis, emphasising the two ways of conception of neutrality; i.e. both as simplicity and as complexity.
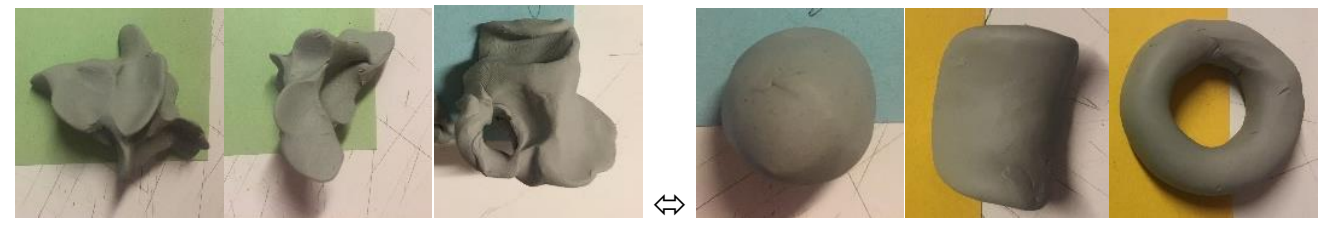

Figure 1. A selection of created neutral forms, based on complexity (left) or simplicity (right).

\subsection{Pre-study 2 - Form neutrality criteria}

As the previous study shows multiple mentions of no extremes, the middle/mean, or neither sides, we build upon the hypothesised simplicity strategy in the further course of this paper. Therefore, the next intermediate step is to define these extremes that must be avoided based on a list of semantic opposite pairs of meanings that are already used in experiential characterisation of materials. However, these meanings are related to materials in general, and we are interested in the meanings that are mostly related to forms in particular. Thus, this pre-study aims to select a set of form-related (forminfluenced) meanings of materials, that can be used as evaluation criteria for neutrality in the next Section.

Again, twenty design students $(\mathrm{N}=20)$ of Product Development are asked to select six out of seventeen semantic opposite pairs that are, according to them, most related to or influenced by form. The results are 
processed by means of a frequency table (see Figure 2). Consequently, the following characteristics are selected for the next research steps: Delicate-Rugged, Aggressive-Calm, Futuristic-Nostalgic, MasculineFeminine, Traditional-Modern, and Toylike-Professional.

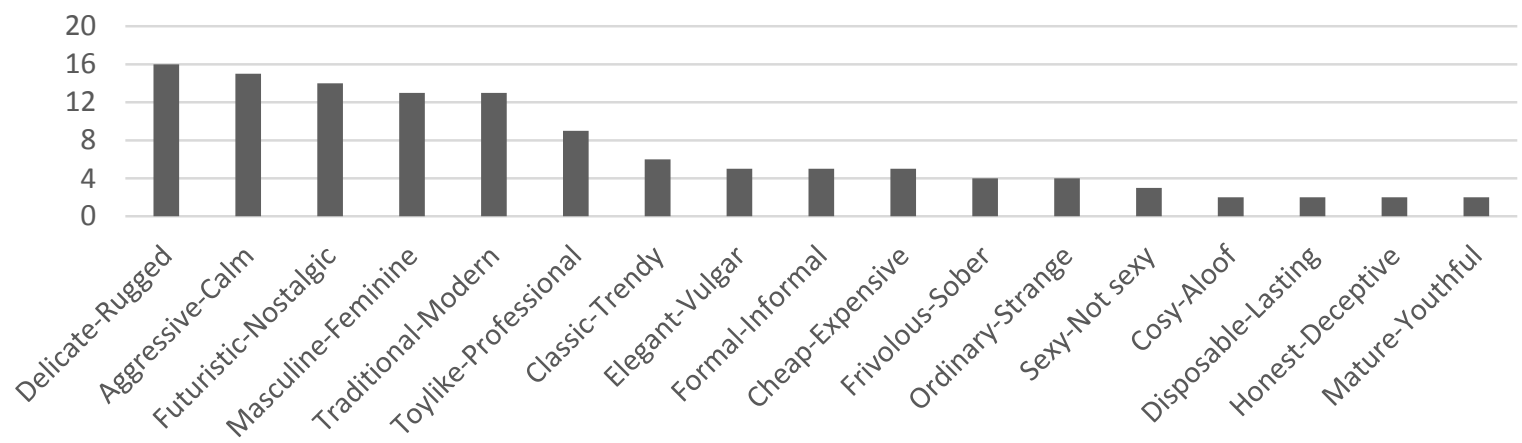

Figure 2. Frequency table of selected semantic pairs

\section{APPROACH TOWARDS A NEUTRAL FORM}

The previous Section explored how neutrality can be defined and characterised. However, in order to create a neutral form, we first have to understand what is not neutral. Therefore, the next Section follows a reverse approach and studies what forms are considered not neutral at all. In this regard, nonneutral forms are chosen as boundaries for the creation of neutral forms, as these extremes are the easiest to shape, yet offer potential to arrive at forms that surpass a plain sphere that offers merely one perspective from all angles. Building upon the simplicity strategy, this approach intends to transition from extreme to neutral by consecutively averaging forms. Figure 3 gives a visual overview of the process flow of the design phases building upon each other's outcomes. This layered structure of successive design steps consists of four phases:

- Phase A: creation of forms for each characteristic of a pair $(6 \times 2 \times 20)$

- Phase B: creation of average forms for each characteristic $(6 \times 2 \times 1)$

- $\quad$ Phase C: creation of average forms for each pair $(6 \times 1)$

- $\quad$ Phase D: creation of average form proposals over all six pairs $(4 \mathrm{x})$

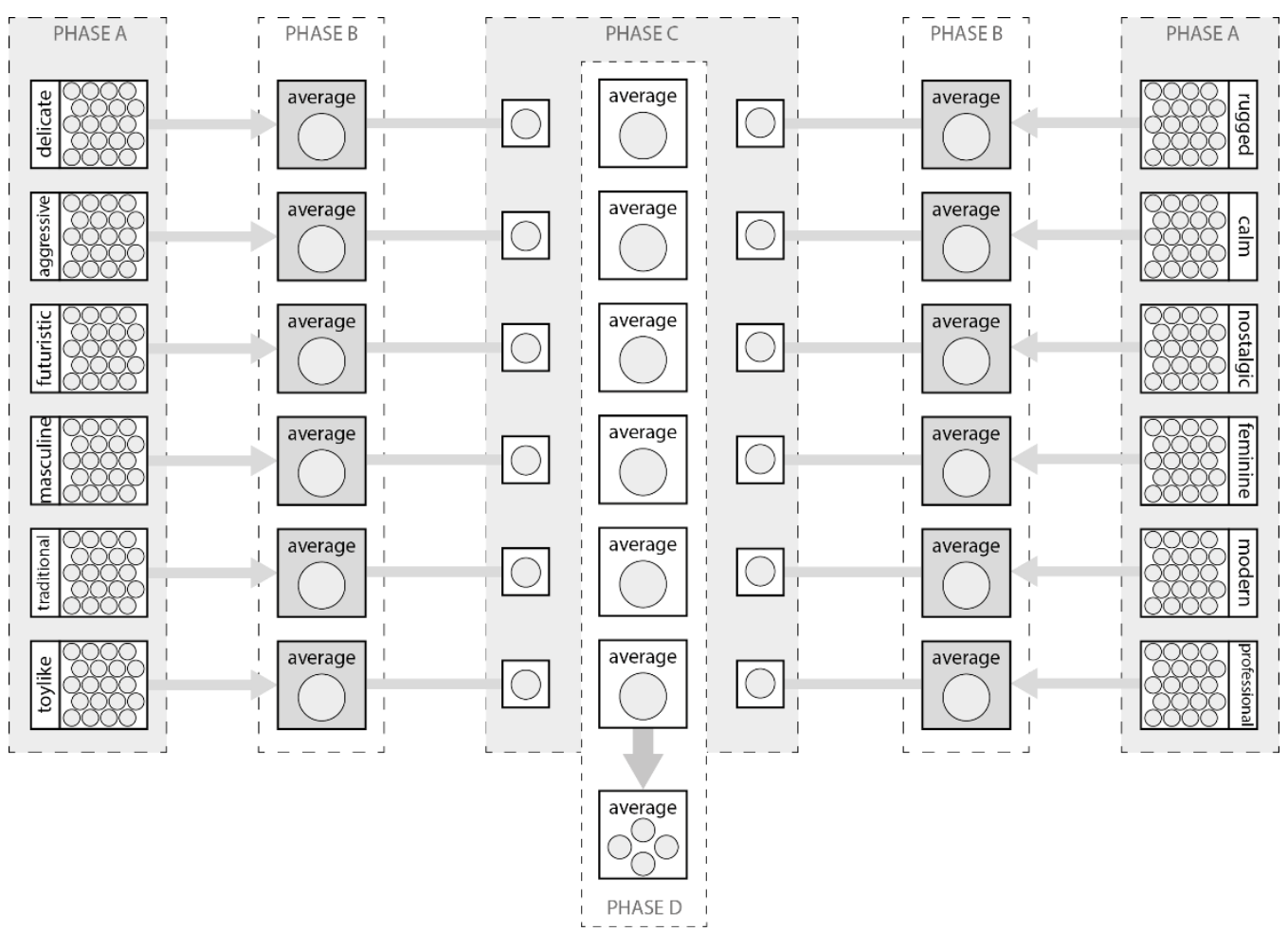

Figure 3. Overview of the different phases towards a neutral form. 


\subsection{Phase A}

The first phase aims to understand what forms are not perceived as neutral by creating forms that are related to the six pairs of adjectives that were selected as 'criteria for neutrality' in Section 4.2. Ten designers and ten non-designers $(\mathrm{N}=20,10$ male and 10 female) voluntarily participate, and are asked to create a form with plasticine for each of twelve characteristics.

A selection of the range of the resulting 240 forms $(6 \times 2 \times 20)$ of this first step are shown in Figure 4 . A first look at the resulting forms shows that for some meanings similarities could be found (such as aggressive-calm), while other meanings (such as futuristic-nostalgic) resulted in a varied collection of rather different forms.

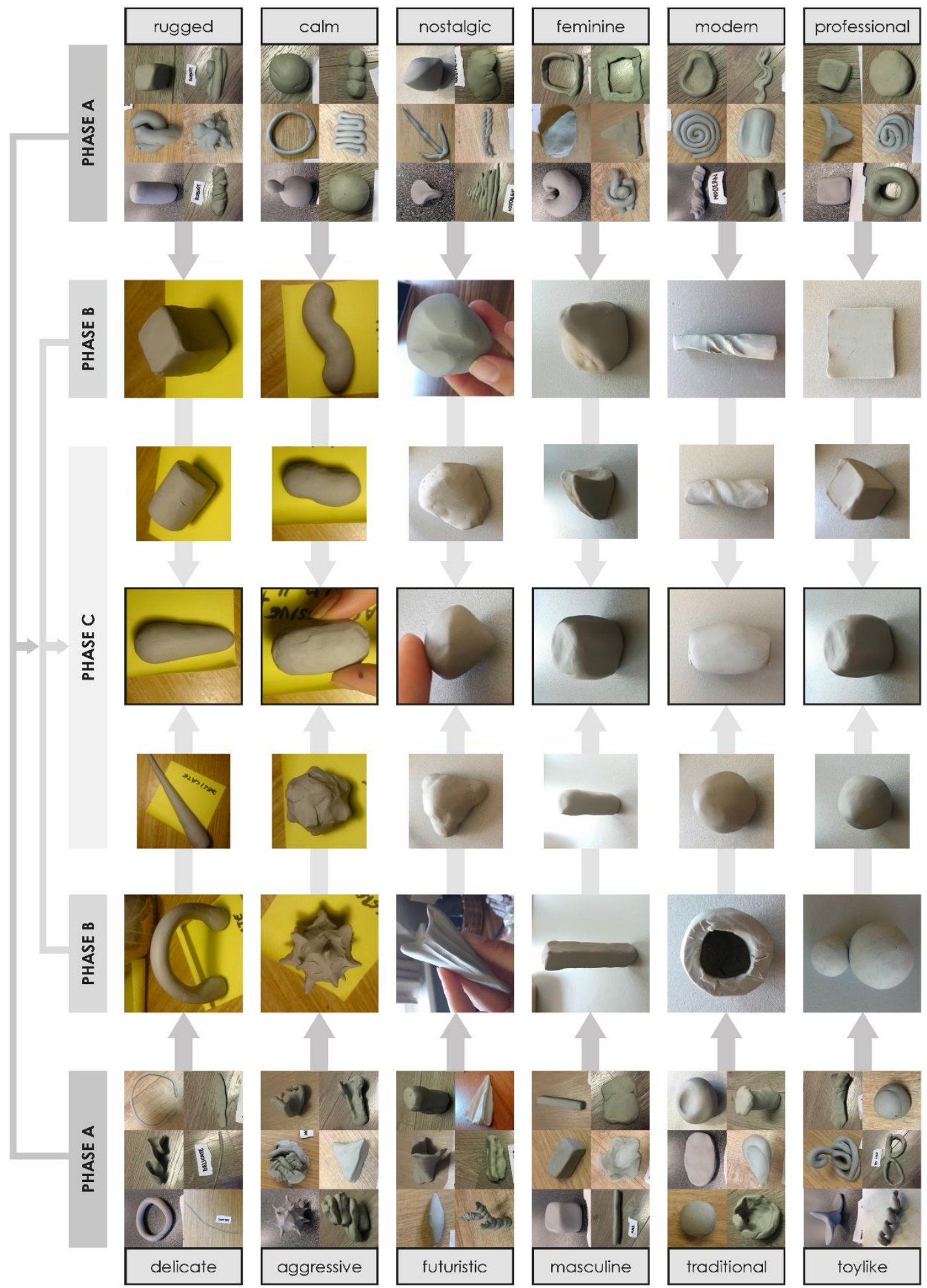

Figure 4. Selection of form results of phase $A, B$, and $C$. 


\subsection{Phase B}

The second phase aims to combine the results of the previous phase (i.e. 20 forms per meaning) into an average form per characteristic. A research team of five designers $(\mathrm{N}=5,2$ male and 3 female) are asked to create a representative form with plasticine for each of twelve characteristics, relying on the forms of phase A. Discussion and collaboration increases the objectivity of the obtained results.

This step results into twelve forms $(6 \times 2)$, each one describing an opposite adjective, that can be used as input for the next workshop. The twelve forms of phase B are also visualised in Figure 4.

\subsection{Phase C}

The third phase aims to bridge the two extreme forms of each set of opposite adjectives by creating an average form for each of the six semantic pairs. It is hypothesised that such an average form should inherit either both meanings at the same time, or none of them. The same five design students $(\mathrm{N}=5,2$ male and 3 female) are asked to merge the opposite average forms into one average plasticine form ('i.e. middle point') for each semantic pair, by means of a three-step process, leading to a representative form. Again, the final forms are obtained through discussion and collaboration of the team to increase objectivity.

This phase resulted in six forms (6x1), each one representing neutrality according to one semantic pair, that can be used as input for the next workshop. Figure 4 shows the 3 -step process from two opposite averages to one neutral form or 'middle point'.

\subsection{Phase D}

The fourth phase aims to create a final neutral form as the average of the six previously proposed 'middle points', combining the common aspects of these forms. The same five design students $(\mathrm{N}=5,2$ male and 3 female) each receive an overview of the results of the third phase and are asked to create four plasticine forms that could represent neutrality. Next, they are asked to evaluate the forms as a team and combine them to reduce the amount of forms to four, according to the neutrality of the form.

\subsubsection{Results}

By means of an intermediate step, leading to twenty $(5 \times 4)$ preliminary neutral forms, this phase finally results in four forms that could all represent neutrality, yet offer more angles than a plain sphere. Figure 5 presents the four selected forms by means of 3D prints. Form $i$ combines a sphere and a cone, which avoids sharp edges and vertex by including a transition between both shapes. By means of concave details it attempts to create interaction with the user and to invite them to touch and experiment with the form. Form ii is based on a pyramid but excluding the aggressive character by rounding the edges, transforming its lines into curves, and including slightly convex and concave surfaces. The interaction becomes intuitive by holding it with both hands, inviting the user to touch and turn. Form iii is a symmetric form based on a cylinder with flat endings that host special finger spots and texture surfaces. Its size and lines make it easy and comfortable to hold. Last, Form iv is a variation on form iii but includes a twist in the middle of the piece, eliminating the symmetry in one of the planes. This variation encourages the user to interact more with the form by turning it in contrast to the balance in the previous form.

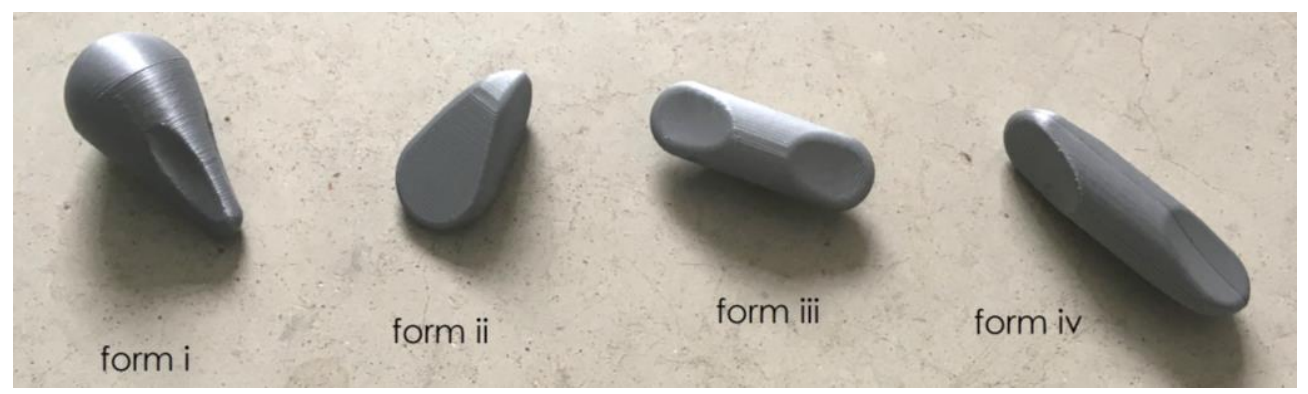

Figure 5. The final four propositions for a neutral material demonstrator form 


\subsubsection{Preliminary verification}

A preliminary verification test with twenty design and non-design students was conducted to evaluate the four proposed forms based on the six criteria of Section 3.2. However, this showed highly dispersed results, showing no significant indications whether the forms were perceived neutral or non-neutral. However, it did reveal that non-designers consider the forms more neutral than designers in all cases. All in all, form iii - followed by the twisted form iv - showed the most relation to neutrality, although no significant claims can be made. We propose further studies that explore the complexity strategy as well, leading to potential neutral forms than can be compared to this study's generated forms, a plain sphere, and existing flat material demonstrators, in order to test the neutrality of all forms.

\section{Discussion}

Regarding the challenges in assessing material samples, the meaning of a material is influenced by context, user and product-related parameters such as product shape and function. Material data on technical properties is widely available, however, in order to provide equivalent data support on experiential material characteristics, a more standardised and objective way is required to assess such materials experience. One way to achieve a more valuable one-to-one comparison is through presenting different materials in one and the same form, with minimal associations to existing products or extreme meanings. Therefore, this paper reasoned upon the conception of neutrality in relation to material exploration and presented an experimental attempt to examine the potential of a neutral form for experiential material characterisation.

As human beings, we tend to give meaning to everything we perceive, in fact, it is a fundamental trait of human intelligence. Thus, we argue that neutrality might not exist at all. We question if it is really possible to create a form that is neutral to everyone. However, things can be more or less neutral than others, and a form might still be neutral enough for material exploration.

Consequently, two opposing conceptions of neutrality were proposed as the base for the further study: neutrality through complexity versus neutrality through simplicity. In this study, we followed the latter strategy, and discussed the qualitative process towards four potential neutral material demonstrator forms, to better support experiential characterisation studies of materials by means of a standardised form, i.e. material representation, allowing materials to be envisioned in different contexts. However, we argue that the followed simplicity methodology might cause too much simplification, and therefore loss of information, because of constantly averaging out. Hence, this research expresses that neutrality through simplicity is not the way to go, as it leads to rather 'boring' forms that conflict with the interactivity to attract and trigger consumers in engaging in extensive material exploration.? Conversely, adding more interactivity to the material form might cause a transition to the complexity strategy.

Moreover, when conducting studies to examine how people experience certain materials, we expect other needs for consumer studies in contrast to designers studying materials themselves. Consumers might have a greater need for interaction to trigger their imagination and facilitate abstract thinking. Therefore, a compromise is required between the need for neutrality and the need for interactivity (i.e. having different perspectives from different viewing angles) when designing a material sample form that is interesting, yet neutral enough to minimise contextual influences.

At the present time, the resulting form proposals rely on a very qualitative approach, that might suffer from a bias using students as participants in the workshops. Yet, its value lies in the reasoning process and the preliminary insights it provided. In this way, we hope to facilitate the experiential characterisation of materials by increasing the standardisation of the material representation, and consequently to facilitate materials selection focussing on a specific target user group. In the context of such standardisation, an additional step will have to focus on the manufacturability of the demonstrator form. For example, when focussing on the material family of plastics alone, the process of injection moulding could offer interesting possibilities once technical form-related issues are overcome. However, when potentially expanding to other material families, this aspect must be reconsidered from the perspective of another adequate processing technique.

Finally, further studies are planned, for example with experts on the field of form or design, in order to discuss what a material evaluation form or demonstrator needs to have or needs to be. Can one standardised form suffice, or does it need to consist of a set of forms, or even modular? As we recognise the fact that more interactivity should be included in a consumer-focused tool, we aim to 
examine the complexity strategy as well to increase the interactivity potential, and to compare the results with the simplicity strategy, and current material demonstrators

\section{CONCLUSION}

In the context of meaningful materials experience in industrial design, there is a clear need for adequate support for experiential characterisation. In order to facilitate systematic large-scale data collection with consumers, a one-to-one comparison of different materials in the same physical 'form' is required, i.e. a standardised material demonstrator that can be used as objective stimuli in experiments.

First of all, we proposed that this demonstrator form must be a physical object to fully enable the sensorial experience. Next, to include the end-user in the characterisation process, it must be attractive and accessible to consumers; it must trigger them to interact with the sample object. Last, it must facilitate an objective comparison between materials, minimising external influences (such as context, product, shape etc.) on associations, hence, the sample form must be as 'neutral' or 'meaning-less' as possible. Therefore, this paper explored the conception of neutrality and proposed two opposing strategies: neutrality through complexity or through simplicity. More specifically, it presented the process of four successive design phases towards the creation of a neutral form, grounding on the latter strategy, that can serve as a material demonstrator in further research.

Consequently, four form proposals have been developed, and although the resulting forms - or the followed strategy - need further adjustments, this qualitative process was instructive and provided useful insights. In conclusion, we argued that the demonstrator form does not need to be neutral, but rather neutral enough for material exploration. As the followed simplicity strategy resulted in too much simplification and a loss of information, we proposed to increase the interactivity by means of the complexity strategy in further research, to trigger consumers in an extensive exploration of standardised material samples.

\section{REFERENCES}

Agost, M.J. and Vergara, M. (2014), "Relationship between meanings, emotions, product preferences and personal values. Application to ceramic tile floorings", Applied Ergonomics, Vol. 45 No. 4, pp. 10761086. https://doi.org/10.1016/j.apergo.2014.01.008.

Ashby, M.F., Bréchet, Y.J.M., Cebon, D. and Salvo, L. (2004), "Selection strategies for materials and processes", Materials \& Design, Vol. 25 No. 1, pp. 51-67. http://dx.doi.org/10.1016/s02613069(03)00159-6.

Ashby, M.F. and Cebon, D. (2007), Teaching Engineering Materials: the CES EduPack.

Ashby, M.F. and Johnson, K. (2012), Materials and Design: The Art and Science of Material Selection in Product Design., Elsevier, Oxford, UK.

Camere, S. and Karana, E. (2018), Experiential characterization of materials: Toward a toolkit, DRS2018: Catalyst, Limmerick. http://dx.doi.org/10.21606/drs.2018.508

Chiner, M. (1988), "Planning of expert systems for materials selection", Materials and Design, Vol. 9 No. 4, pp. 195-203. http://dx.doi.org/10.1016/0261-3069(88)90031-3.

Crippa, G., Rognoli, V. and Levi, M. (2012), "Materials and emotions: A study on the relations between materials and emotions in industrial products", 8th International Design and Emotion Conference, London.

Deng, Y.M. and Edwards, K.L. (2007), "The role of materials identification and selection in engineering design", Materials and Design, Vol. 28 No. 1, pp. 131-139. http://dx.doi.org/10.1016/j.matdes.2005.05.003.

Etzi, R., Spence, C. and Gallace, A. (2014), “Textures that we like to touch: An experimental study of aesthetic preferences for tactile stimuli”, Consciousness and Cognition, Vol. 29, pp. 178-188. http://dx.doi.org/10.1016/j.concog.2014.08.011.

Farag, M.M. (2002), "Quantitative methods of materials selection", in Kutz, M. (Ed.), Handbook of Materials Selection, John Wiley \& Sons, New York, pp. 466-488. https://doi.org/10.1002/9780470172551.ch1

Fenko, A., Schifferstein, H.N.J. and Hekkert, P. (2010), "Looking hot or feeling hot: What determines the product experience of warmth?”, Materials \& Design, Vol. 31 No. 3, pp. 1325-1331. http://dx.doi.org/10.1016/j.matdes.2009.09.008.

Granta. (2016), CES EduPack - Products, Materials and Processes database, Granta. Available at: http://www.grantadesign.com/education/editions/products.htm (accessed 18 May 2016).

Hassenzahl, M. (2013), "User Experience and Experience Design", The Encyclopedia of Human-Computer Interaction, 2nd Ed.

Hodgson, S.N.B. and Harper, J.F. (2004), "Effective Use of Materials in the Design Process: More Than a Selection Problem", DS 33: Proceedings of E\&PDE 2004, the 7th International Conference on 
Engineering and Product Design Education, Delft, the Netherlands, 02.-03.09.2004, Delft, the Netherlands, pp. 593-601.

Jalham, I.S. (2006), "Decision-making integrated information technology (IIT) approach for material selection", International Journal of Computer Applications in Technology, Vol. 25 No. 1, pp. 65. http://dx.doi.org/10.1504/ijcat.2006.008669.

Karana, E. (2009), Meanings of Materials (Doctoral Dissertation), Delft University of Technology, Delft, the Netherlands.

Karana, E., Hekkert, P. and Kandachar, P. (2009), “Assessing material properties on sensorial scales”, 2009 ASME International Design Engineering Technical Conferences and Computers and Information in Engineering Conference, DETC2009, Vol. 2, pp. 911-916. http://dx.doi.org/10.1115/detc2009-86756

Karana, E., Hekkert, P. and Kandachar, P. (2010), "A tool for meaning driven materials selection", Materials and Design, Vol. 31 No. 6, pp. 2932-2941. http://dx.doi.org/10.1016/j.matdes.2009.12.021.

Karana, E., Weelderen, W. van and Woerden, E.-J. van. (2007), "The Effect of Form on Attributing Meanings to Materials", American Society of Mechanical Engineers, pp. 471-487. http://dx.doi.org/10.1115/detc2007-34646

Van Kesteren, I.E.H. (2008), Selecting materials in product design (Doctoral dissertation), TU Delft, Delft University of Technology, 7 January, available at: http://repository.tudelft.nl/view/ir/uuid:23ad12d6-f7a3485b-be42-797256b9e5bc/.

Van Kesteren, I.E.H., Kandachar, P. and Stappers, P.J. (2006), “Activities in selecting materials by product designers", Proceedings of the International Conference on Advanced Design and Manufacture.

Krippendorff, K. and Butter, R. (1984), "Product Semantics: Exploring the Symbolic Qualities of Form", Innovation, Vol. 3 No. 2, pp. 4-9.

Material District. (2019), Materials Archive - MaterialDistrict, available at: https://materialdistrict.com/material/\#moved (accessed 18 March 2019).

Muller, W. (2001), Order and Meaning in Design, Lemma, Utrecht.

Osgood, C.E., Suci, G.J. and Tannenbaum, P.H. (1957), The Measurement of Meaning, University of Illinois Press, USA.

Piselli, A., Baxter, W., Simonato, M., Del Curto, B. and Aurisicchio, M. (2018), "Development and evaluation of a methodology to integrate technical and sensorial properties in materials selection", Materials \& Design, Elsevier, Vol. 153, pp. 259-272. http://dx.doi.org/10.1016/j.matdes.2018.04.081.

Ramalhete, P.S., Senos, A.M.R. and Aguiar, C. (2010), "Digital tools for material selection in product design", Materials \& Design, Vol. 31 No. 5, pp. 2275-2287. http://dx.doi.org/10.1016/j.matdes.2009.12.013.

Sakamoto, M. and Watanabe, J. (2017), "Exploring Tactile Perceptual Dimensions Using Materials Associated with Sensory Vocabulary", Frontiers in Psychology, Frontiers, Vol. 8, pp. 569. http://dx.doi.org/10.3389/fpsyg.2017.00569.

Sauerwein, M., Karana, E. and Rognoli, V. (2017), "Revived Beauty: Research into Aesthetic Appreciation of Materials to Valorise Materials from Waste", Sustainability, Multidisciplinary Digital Publishing Institute, Vol. 9 No. 4, pp. 529. http://dx.doi.org/10.3390/su9040529.

Thaler, R.H. and Sunstein, C.R. (2008), Nudge: Improving Decisions About Health, Wealth, and Happiness, Yale University Press, New Haven.

Veelaert, L., Du Bois, E., Hubo, S., Van Kets, K. and Ragaert, K. (2017a), "Design from Recycling”, EKSIG2017: Alive, Active, Adaptive : International Conference on Experiential Knowledge, Rotterdam, the Netherlands, pp. 129-143.

Veelaert, L., Hubo, S., Ragaert, K., Van Doorsselaer, K. and Du Bois, E. (2017b), Determinator Design Box \& Booklets - Design From Recycling, Antwerp, available at: http://hdl.handle.net/10067/1472460151162165141.

Veelaert, L., Moons, I., Coppieters, W. and Du Bois, E. (2018), “Exploring the Fit Between Materials' Expressive Values and the Self-expression of the End-User", 20th Congress of the International Ergonomics Association, pp. 2045-2066. http://dx.doi.org/10.1007/978-3-319-96071-5_215

Wastiels, L., Schifferstein, H.N.J., Heylighen, A. and Wouters, I. (2012), "Red or rough, what makes materials warmer?", Materials \& Design, Elsevier, Vol. 42, pp. 441-449. http://dx.doi.org/10.1016/j.matdes.2012.06.028.

Zarandi, M.H.F., Mansour, S., Hosseinijou, S.A. and Avazbeigi, M. (2011), “A material selection methodology and expert system for sustainable product design", International Journal of Advanced Manufacturing Technology, Vol. 57 No. 9-12, pp. 885-903. http://dx.doi.org/10.1007/s00170-011-3362-y.

Zuo, H., Jones, M., Castle, P. and Hope, T. (2001), "An investigation into the sensory properties of materials", The Second International Conference on Affective Human Factors Design, Singapore, available at: http://ssudl.solent.ac.uk/92/

\section{ACKNOWLEDGMENTS}

We would like to acknowledge Eva Wenborn, Tereza Vacková, Gloria Diaz, Eduard Casadevall and Adriá Fenollosa, our team of five international designers for their input in creating the average forms. 